DRUG DELIVERY

\title{
Nanoparticles improve profile of molecularly targeted cancer drug
}

\begin{tabular}{|c|c|}
\hline $\begin{array}{l}\text { slow-releasing } \\
\text { Accurins could } \\
\text { have better } \\
\text { safety profiles } \\
\end{array}$ & $\begin{array}{l}\text { Nanoparticles have been used to } \\
\text { encapsulate and deliver traditional } \\
\text { chemotherapeutic agents, such } \\
\text { as doxorubicin or paclitaxel, } \\
\text { to target tissues. A recent article goes } \\
\text { one step further, using polymeric } \\
\text { nanoparticles termed Accurins to } \\
\text { deliver a molecularly targeted agent } \\
\text { to tumours in rodents, thereby } \\
\text { side-stepping issues with toxicity } \\
\text { and drug clearance that were } \\
\text { apparent with unencapsulated } \\
\text { versions of the drug. } \\
\text { AZD2811 is a small-molecule } \\
\text { inhibitor of Aurora B kinase. } \\
\text { Aurora B is required for cytokinesis, } \\
\text { and inhibition of this kinase leads } \\
\text { to mitotic catastrophe. A prodrug } \\
\text { of this inhibitor, AZD1152, has }\end{array}$ \\
\hline
\end{tabular}

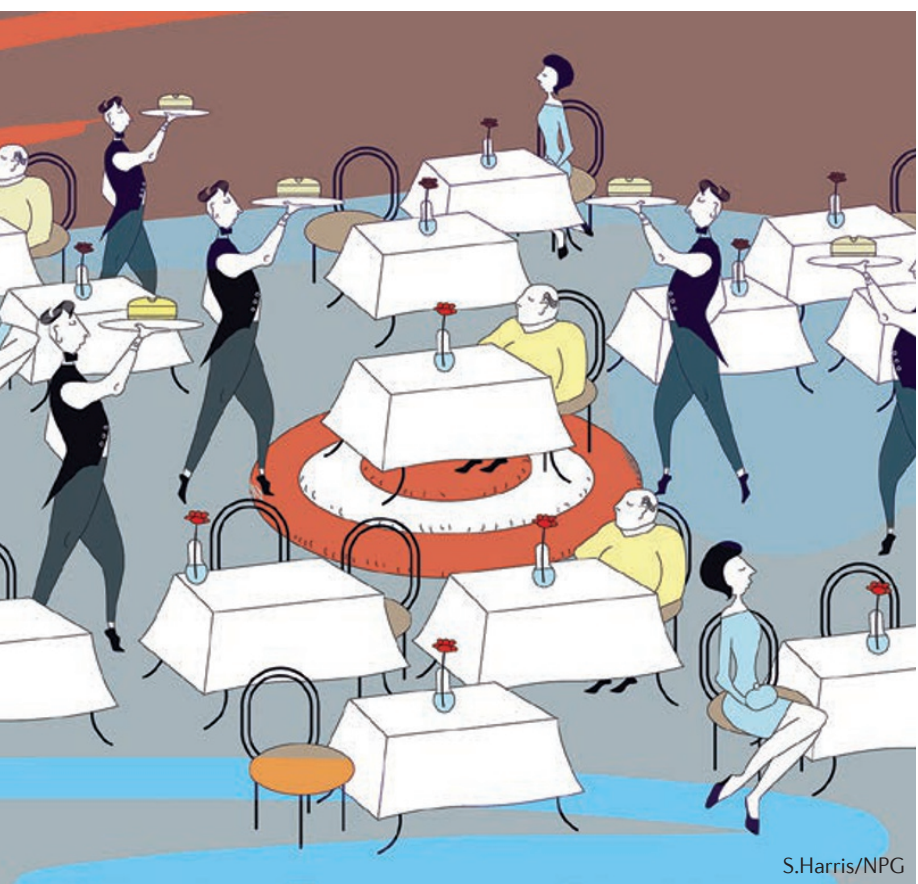

been examined in clinical trials, and the drug had clinical benefit - it increased the complete response rate in patients with acute myeloid leukaemia - but required continuous intravenous infusion. Development of the drug has also been limited by toxic effects, including myelosuppression, particularly in patients with solid tumours. The developers therefore sought novel ways to deliver the drug more safely.

Previously, encapsulation of drugs using nanoparticles made from co-polymers of poly-D,L-lactide and polyethylene glycol has been shown to increase drug concentrations specifically in tumours. To increase the solubility of AZD2811 in the organic solvents used to make the nanoparticles, the investigators added monovalent and divalent carboxylic and sulfonic organic acids to the solution as ion pairing agents. They synthesized a range of AZD2811-containing nanoparticles with oleic, xinafoic, trifluoroacetic or dioctyl sulfosuccinic acid in different concentrations, designated Accurin A to F, and examined their effects in vivo.

Plasma drug concentrations (which includes both encapsulated and released drug) in rats intravenously injected with the nanoparticles were approximately two orders of magnitude higher than those in rats treated with AZD1152, and the drug was detectable more than 20 days after Accurin administration. In nude rats bearing human colorectal adenocarcinoma xenografts, AZD1152 reduced tumour levels of phosphorylated histone $\mathrm{H} 3$ (pHH3), a marker of mitosis, within 6 hours, and levels recovered within 24 hours. Most of the Accurins also reduced intratumoural $\mathrm{pHH} 3$ levels within 6 hours, and these levels only recovered after 72 hours. Accurin E released drug most slowly: $\mathrm{pHH} 3$ inhibition declined steadily over at least 96 hours.

Two doses of Accurin B or E (on days 1 and 3 ) inhibited tumour growth in these rat xenograft models by $92 \%$ and $101 \%$, respectively. By comparison, daily treatment of mice with AZD1152 for 4 days inhibited tumour growth by only $58 \%$. These results are supported by similar xenograft experiments in mice, including engraftment of diffuse large B cell lymphoma cell lines.

In rats, Accurin E had minimal effects on bone marrow cellularity and lymphoid and myeloid cell numbers over 15 days, whereas AZD1152 and Accurin B reversibly reduced bone marrow cellularity by day 5 , suggesting that slow-releasing Accurins could have better safety profiles. The slow-releasing Accurins ( $\mathrm{E}$ and $\mathrm{F}$ ) released active drug with similar kinetics in tumours; whereas the active drug was undetectable in tumours of rats treated with AZD1152 by 24 hours, the active, unencapsulated drug was detectable in rats treated with Accurin F up to 6 days after treatment.

Nanoparticle encapsulation and ion pairing could enable other molecularly targeted agents, including kinase inhibitors otherwise limited by toxicity, to be used effectively in the clinic .

Megan Cully

ORIGINAL ARTICLE Ashton, S. et al. Aurora kinase inhibitor nanoparticles target tumors with favorable therapeutic index in vivo. Sci. Transl. Med. 8, 325 ra17 (2016)

FURTHER READING Torchilin, V. P. Multifunctional, stimuli-sensitive nanoparticulate systems for drug delivery. Nat. Rev. Drug Discov. 13, 813-827 (2014) 